\title{
Research on the Significance and Necessity of Conducting Professional Sketch Course on Freehand Figure Painting Education
}

\author{
Ju Rong ${ }^{1}$, Shao Zhaoyang ${ }^{2}$ \\ ${ }^{1,2}$ Agricultural University of Hebei \\ hunter2011@foxmail.com
}

Keywords: Professional Sketch, Painting Education, Freehand Figure Painting.

\begin{abstract}
Sketch is the foundation of every painting language, it is one of the important basic skills impressionistic portraits. Today Chinese painting freehand figures show there is stiff modeling language to convey the confusion, showing the contents of a series of questions out of touch with life, etc., but sketch medicine is to solve this problem. Therefore, on the basis of general education sketch, sketch classification refinement, strengthening and promoting professional conduct sketches, freehand sketching portraits for the study of the role of, impressionistic portrait of the artistic skills upgrade has a very profound theoretical and practical significance.
\end{abstract}

\section{Introduction}

Chinese painting, especially impressionistic portrait of artistic creation is inseparable from the sketches, sketches a painter living in life experience and observation process inspiration accumulated crystallization. Art must be natural and real as the source of nourishment subjective emotions. A sketch of each, it is the image of our hearts track recording and reproducing, we continue to accumulate wealth of art from life to the art of this process. Sketch training is a long-term work, we must persevere, over time, the formation of consciousness, but sketches, especially more in line with the characteristics of Chinese painting teaching professional sketches, set the stage in teaching art institutions did not occupy its rightful place. Although a growing number of art institutions have begun to realize the role of sketches for painting, but on a professional sketch curriculum system with strong characteristics of Chinese painting is not perfect, even still vacancies in certain institutions, how to refine the sketch classification, and carry out painting sketch teaching more in line with their professional characteristics, it has become a new topic.

\section{Sketch Tradition of Chinese Painters}

Chinese artist has been focusing on sketches, especially impressionistic figure painter, has even sketches as day courses and creative inspiration and basis. Mr. Ye Qianyu stick with sketches of his life recorded live, we can say that his achievement is the root of Chinese painting based on sketches. "Do not draw the curtain in the dance, to draw chest of dance" is the greatest works of Ye Qianyu dancing figures artistic qualities. This is the secret associated with his long sketch training. By sketching language, to make Yip character drama and dance moves adequately concise and honed. The Remarkable achievement of Mr. Huang Zhou is based on sketches, as an outstanding figure painter Huang Zhou especially deeply realize the importance of sketches of figure painting. He said such a sentence: "sketches and sketches should always painting, painting every day for three years to stop the disease for nine years, a good time of a person's life will almost sketch artist could not stop not before, at least himself, have a sense of depth. "Huang Zhou often said," a painter, if left to live, not live in sketches, not life collecting material, whether the painter is, his work would slowly lose its luster.

It can be said that many of the older generation has always focused on artist sketch training, emphasizing the role of sketch in the basic training of Chinese painting, and personally to adhere to the sketch and painting practice integration. Chinese traditional painting style method relies too much on memory the way it not only by direct memory ability, but also to the motion, the changing 
things there is a keen and profound observation and understanding, to seize the important objective image features and the intrinsic link to afford Global Impression, make images live in the hearts of the painter, and then refined, broad, exaggerated. in unique artistic language to convey to the audience. From this perspective, the role of Chinese painting shape sketch in basic training in the more cannot be ignored.

\section{The Significance and Necessity of Conducting Professional Sketch Course on Freehand Figure Painting Education}

Basic teaching of Chinese painting cannot be in isolation, cannot appear on the students complete similar drawings, sketches on the basis of after-school put the drawing board and sketchbook shelved, otherwise teaching basic courses of action will be greatly reduced. Moreover, Chinese painting professional foundation courses also need late courses are closely around the penetration resistance, such as copying lessons, painting classes, writing classes, etc., should form the teaching link organic whole, should have a main line runs through teaching. The main line should be creative, independent creation of students, whether it is the basic course or teaching courses, should be for the creation of services to enhance the students' creative ability of comprehensive primary objective. As a result, the foothold painting professional basic course of reform should also be located in this station, both how to make teaching more favorable basis for future professional painting creation.

From now on the basis of teaching overall situation, most institutions still followed the so-called "traditional" teaching mode, such as drawings, sketches kind of basic courses and subsequent professional courses, especially courses in painting convergence situation is far from ideal and even split. This little break Duoxu curriculum model is not going to make real contact with students in painting courses, suffered a very painful process of transformation, whether it is painting techniques or artistic thinking, which seriously hampered the development of professional teaching painting is our We had to be given attention.

At the same time we should also note that for different professional sketch teaching mode and training content must not single, unified way to carry out specific criteria or teaching. Especially for painting professional, if a camel is directly apply to light briquettes West sketch based training courses for the professional conduct of subsequent painting it is very unfavorable. So be sure to further refine the sketch program, set up in line with the teaching of sketch painting courses make it more in line with the teaching content and form of artistic expression painting, more in line with traditional Chinese painting in particular freehand character modeling language requirements, which for freehand character education Construction to carry out scientific and system has far-reaching significance.

\section{The Teaching Professional Approach and the Specific Implementation Method of Painting Sketch}

Based on $\mathrm{Mr}$. Xu Beihong painting emphasis on modeling and sketching teaching ideas, Mr. Jiang Zhaohe combined with their actual experience of artistic creation, will be footing with research focus on teaching reform for "painting traditional language - sketch modeling capabilities art" These three the relationship between those who, in order to explore the issue of teaching the basic course of modeling painting. After many years of teaching practice and summarize research, the creation of a "line drawing of the shape of the foundation, in order to sketch the reform of teaching as the central link" of painting character sketch teaching system. He asked Mr. Jiang Zhaohe simultaneously conducting training in drawing dictation, sketch exercises. This teaching method is also the basis for further study of traditional Chinese painting shape laws laid.

The Training of Linear Sketch. Linear sketch training at this stage is an important part of the way from the traditional sketch show sketch to painting professional transition. In this session, students can still use their familiar material tools such as Pen (pencil, pen) and sketch paper, but in the specific form of expression requires light and shade they gradually disengage completely with 
lines, change their order light mass-based visual and artistic way of thinking inertia, aside interference changing light and shade, Watch lines essence.

Line Drawing Sketch Training. In this session, students will replace hard brush, brush and rice paper sketch paper is thus closer to the nature of freehand drawing figures fundamentally. Guide students 'freehand' perspective to observe objects, take bold steps to refine the essential characteristics of the object and to performance. In the expression, we want to shape, trying to overcome the conventional rigid lines in Pen sketch, straightforward expression, Chinese painting experience artistically vivid pen and bone artistic pursuit. Strengthen students' sensibility and expressive line, through the grasp and understanding of different lines, rich picture performance, the mention by frustrated, priorities and the twists and turns of rhythm, the guide students to understand China's unique freehand painting spirit, and "write" and "meaning" the real meaning.

Ink Sketch Training. Core and backbone of Chinese painting is actually calligraphy, Chinese painting language meaning the vast majority come from the pen calligraphy pen. Chinese painting is written out, not describe it, so to keep practicing calligraphy to understanding Chinese painting impressionistic lyrical academic character, so that ink pen, ink pen. Throughout the history of Chinese ink painting, especially the history of calligraphy painting people "writing sex" has occupied a very important position and become the standard tasting ink aesthetic rules. Tang Dynasty, Zhang Yan Yuan said: "spineless shape are present at conception, and go almost a pen, so workers who draw more good books." Visible, Chinese painting and calligraphy are intrinsically linked, whether the line of Chinese painting has the intensity, rhythmic, there calligraphy pen charm is an important indicator to measure the pros and cons of the lines. Do not have the basic skills of calligraphy, by the death would not have to pull the hard grind vivid ink figure painting. Painters have such an experience, ink figure painting, calligraphy demanded by straight express feelings, to have meaning calligraphic line was written shape.

\section{Conclusion}

From artistic language expressive aspect, the nature of the sketch freehand line meet with the spirit of Chinese painting, Chinese painting style language requires not only have the ability to face images accurately painter sketch artist, but also more emphasis on energy projects in mind to create images know the heart and by line generalization, concise, certain "write" the emotion, which requires the artist must be highly refined image content and can quickly, accurately to the performance, in painting sketch professional training is an important means to carry out training students modeling ability, and it is learning prerequisites for Chinese ink painting techniques.

\section{Acknowledgements}

Project number: K13-08 (This Project is the Key Research Result of Agricultural University of Hebei Curriculum Construction)

Project name: Freehand Figure Painting

\section{References}

[1] Wang-Shou Y. New Performance Character Sketches. People's Fine Arts, 2006, 6(1).

[2] Wang-Haiqing. Character Sketch Sketch Art College Entrance Examination Papers Policy Analysis. Journal of Radio and Television University, 2014, 11(6).

[3] Sun H. Sketch Primary Curriculum: Landscape Sketch, 2012, 10(4).

[4] Zhang M, Qu J, Bai H. Character Sketch Techniques. Several Fashion (New Visual Arts), 2013, 11(10).

[5] Chen-Li F. Character Sketches. Visual Communications \& Image Processing, 2013, 2(10). 